\title{
Factors Associated with Psychological Well-being among Parents of a Critically Ill Child in Pediatric Intensive Care Unit
}

\section{Jiraporn PUNYOO ${ }^{1}$, Linchong POTHIBAN ${ }^{1, *}$, Usanee JINTRAWET $^{\mathbf{1}}$, Jutarat MESUKKO ${ }^{1}$ and Sanit REUNGRONGRAT ${ }^{2}$}

\author{
${ }^{1}$ Faculty of Nursing, Chiang Mai University, Chiang Mai 50200, Thailand \\ ${ }^{2}$ Faculty of Medicine, Chiang Mai University, Chiang Mai 50200, Thailand
}

("Corresponding author's e-mail: linchong.p@cmu.ac.th)

Received: 8 February 2018, Revised: 24 August 2018, Accepted: 20 September 2018

\begin{abstract}
A child's hospitalization in a pediatric intensive care unit (PICU) is a stressful and suffering situation affecting the parents. This correlational study aims to investigate the predicting factors of parents' psychological well-being with regard to a critically ill child in the PICU. The participants were 100 parents with a child hospitalized in one of the five PICUs of five tertiary hospitals. The research instruments included the Demographic Recording Form, the Child's Behavioral and Emotional Responses Scale, the Sense of Coherence Scale-Short Form (SOC-13), Thai Version, the Jalowiec Coping Scale (JCS), the Buddhist Belief Questionnaire, the Modified Version of Social Support Questionnaire, Thai Version, and the Psychological General Well-Being Index (PGWBI). Data were analyzed using descriptive statistics, Pearson's correlation, Spearman's rank correlation coefficient, and hierarchical multiple regression. The results of hierarchical multiple regression showed that religious belief, the child's behavioral and emotional responses, sense of coherence, coping, and social support could explain $36 \%$ of the variance in the psychological well-being of parents of a critically ill child. The factors that made significant contributions to the model were religious belief $(\beta=0.29, \mathrm{p}<0.01)$, sense of coherence $(\beta=$ $0.27, p<0.01)$, the child's behavioral and emotional responses $(\beta=-0.24, p<0.01)$, social support $(\beta=$ $0.22, \mathrm{p}<0.05)$, and coping $(\beta=0.17, \mathrm{p}<0.05)$. The results of this study may serve as preliminary information for nurses in planning nursing interventions in order to enhance the psychological well-being of the parents.
\end{abstract}

Keywords: Critical illness, parents, psychological well-being, pediatric intensive care unit (PICU)

\section{Introduction}

Hospitalization of a child in a pediatric intensive care unit (PICU) for a life-threatening condition is an extremely stressful situation affecting both children and their families. In Thailand, approximately 10 $\%$ of all pediatric patients are admitted to a PICU [1]. The prevalence of critically ill children in the PICU of Ramathibodi Hospital during 2015 to 2016 was 545 children (12.24\% of all hospitalized children) and 558 children ( $11.95 \%$ of all hospitalized children) cases, respectively [2]. In addition, such prevalence of Maharaj Nakorn Chiang Mai Hospital during 2015 to 2016 appeared to be 387 children $(8 \%$ of all hospitalized children) and 507 children (10.04\% of all hospitalized children [3]). The previous studies reported that most parents or caregivers of hospitalized child showed negative emotional responses such as stress, anxiety, depression, and so on [4-6]. Moreover, the long-term effects of hospitalization in PICU on parents showed that anxiety, distress, and depressive symptoms could last for months following PICU discharge [7]. Therefore, this situation may affect the parents' psychological well-being, one of the essential goals of acute care nursing. 
Psychological well-being of parents is a vital component in the care of a seriously ill child. High psychological well-being affects parents and child positively [8]. The parents will be able to cope well with the problems encountered and participate more in the caring $[9,10]$ leading to faster recovery of the child's health and reduced length of stay [11]. On the other hand, parents with decreased psychological well-being are certainly not in state of well-being and if this persists for a long time, it will affect the parent's health [12]. Reduced psychological well-being impacts the physical well-being of parents. Many physical symptoms were reported including headache, fatigue, low energy, sleep, and eating disturbance $[6,13]$. Lee and Kimble [14] reported sleep disturbance, particularly, in mothers of infants hospitalized in the neonatal intensive care unit (NICU), resulting in fatigue and diminished well-being. The declining physical state of parents can affect their ability in childcare. The compromised psychological well-being of parents also affects the ill child's well-being. Parents with high anxiety or stress are susceptible to less attention, perception, and learning, leading to poor childcare as well as poor parental role performance. Not only is the ill child affected but also the other healthy children will also potentially suffer from the parents' unwell state. Other children in the family may feel abandoned, leading to poor sibling relationships and family conflict $[6,15]$. Therefore, hospitalization of a critically ill child in a PICU has been identified as a tragic and stressful experience for parents and/or other family caregivers. All the encountered problems, therefore, negatively affect on the parents' psychological state.

From literature review, psychological well-being is a broad concept with which a wide variety of terms are offered by different scholars. Ryff [16,17] viewed psychological well-being as engagement in existential challenges of life and positive psychological functioning. She distinguished six dimensions of psychological well-being including autonomy, environmental mastery, personal growth, purpose in life, positive relations with others, and self-acceptance. Keyes [18] proposed that psychological well-being is a term use synonymously with subjective well-being and sometimes specifically refers to a specific kind of subjective well-being. Moreover, Dupuy [19] views psychological well-being as an interpersonal affective or emotional state of people towards their current life situations reflecting a sense of subjective well-being or distress. There are six dimensions of psychological well-being, including anxiety, depression, general health, positive well-being, self-control, and vitality [19]. Psychological well-being is one of three components of mental health [20]. High psychological well-being reflects sound mental health state at which, individual realize their own potential and can cope effective with stress [21]. Therefore, the psychological well-being of parents is a very important concept about which the healthcare provider should be concerned so that it can be sustained at an optimal level.

In order to effectively enhance the parents' psychological well-being, healthcare providers need sufficient information and understanding of this particular state and its influencing factors. Unfortunately, there is little existing knowledge available. From a literature review, only one study in Thailand reported the relationship between a few selected factors including parents' education, uncertainty in illness emotional focused coping, and well-being $(\mathrm{r}=0.32,-0.55,-0.46$, respectively, $\mathrm{p}<0.01)$ [22]. Other variables also may be related to psychological well-being but have not been reported before. The psychological well-being of parents may be explained as the outcome of process by the Stress Process Model (SPM). The original SPM model was developed by Pearlin, Menaghan, Liebrman, and Mullan in 1981. It consisted of three major conceptual domains, including the sources of stress, the mediators of stress, and the manifestations of stress. In 1990, the SPM was revised by Pearlin, Mullan, Semple, and Skaff. The SPM model consists of four components: 1) the background and context of stress, 2) the stressors, 3) the mediators of stress and 4) the outcomes [23]. The SPM is often applied to describe the psychological state of caregivers of patients with many chronic illnesses [24]. Based on the SPM, having a child hospitalized in PICU and the child's negative behavior and emotional response to illness are the situation that the parents appraise as causing harm/loss or threat to the parents. Parents' psychological well-being may be associated with the parent's characteristics, particularly religious belief, stressor in the PICU that is the child's behavior and emotional responses, and the mediators of stress including coping, social support, and sense of coherence. Therefore, this study aimed to investigate the association between such factors and the psychological well-being of the parents of a critically ill child in Pediatric Intensive Care Unit. 
The child's behavioral and emotional responses are considered as primary stressors to the parents. The responses referred to the child's behaviors and emotional expressions towards to pain, discomfort or other critical states including crying, frightening, restlessness, demanding behavior, acting or looking as if in pain, uncooperativeness, inability to talk or cry, anger, and sadness [15]. These behaviors are found to be related to parental stress that reflects their psychological well-being during their child's admission in PICU [15]. A previous study also showed that the perceived infant's behavior and appearance was positively correlated with negative psychological state such as anxiety $(r=0.62, p<0.01)$ and depression $(\mathrm{r}=0.37, \mathrm{p}<0.05)$ among parents with a critically ill child in PICU [13]. Parents' sense of coherence is another potential factor influencing their psychological well-being. Antonovsky [25] defined sense of coherence (SOC) as a global orientation that expresses the extent to which one has a pervasive, enduring though dynamic feeling of confidence that one's environment is predictable and that things will work out as well as can reasonably be expected. The SOC consisted of comprehensibility, manageability and meaningfulness and was proposed to affect the persons' appraisal of situations and to help them better adapt or cope with their stressors [25]. SOC was positively related to the psychological well-being of caregivers of stroke victims $(r=0.31, \mathrm{p}<0.01)$ [26], and was negatively related to stress and depression among mothers of children with autism $(\mathrm{r}=-0.61, \mathrm{p}<0.001)$ [27], and mothers of children with intellectual disability $(\mathrm{r}=-0.72, \mathrm{p}<0.01)$ [28]. Another variable proposed to be a related factor in this study is coping, Lazarus and Folkman [29] defined coping as "a constantly changing cognitive and behavioral effort to manage specific external and/or internal demands that are appraised as taxing or exceeding the resources of the person." Coping was the mediator or the buffer against stressors in the SPM [23]. To cope with stressors in a PICU, a prior study showed that all parents used a combination of both problem-focused and emotion-focused approaches in order to feel well [30].

Religious belief is another proposed variable. In SPM, it is a caregiver characteristic that affects the outcome of the stress process, psychological well-being. Religious beliefs are the fundamental level of religiosity and set of ideological commitments, acceptance, and trust in any religions [31]. From the extensively reviewed literature, Colón-Bacó [32] proposed that religious beliefs are the key component of religious life. She reported that strong religious beliefs were positively correlated with subjective wellbeing. In Thailand, about $94.60 \%$ of Thai population is Buddhist while 4.60 and $0.70 \%$ are Islam and Christians respectively [33]. Therefore, Buddhist belief is dominant in Thai population. Moreover, Koenig [34] proposed that the emotional suffering caused by loss or change may be diminished through religious beliefs or practices. Additionally, the previous study by Kaliampos and Roussi [35] suggested that there were trends indicating that religious belief had negatively predicted psychological distress in subgroups of Greek cancer patients that include stage IV cancer patients. Social support is also included in the present study. According to Schaefer, Coyne, and Lazarus [36], social support was viewed as available emotional, tangible, and informational assistance from others. In the SPM, social support is also viewed as a mediator helping persons to cope with stress thereby increasing psychological well-being [23]. A positive relationship between perceived social support and well-being was reported in caregivers with neuro-cognitive disorders $(r=0.34, p<0.01)$ [37], and in Thai caregivers of Thalassemic children $(r$ $=0.48, \mathrm{p}<0.05)[38]$.

As literature reviews showed that there is little existing knowledge regarding levels of psychological well-being in association with the parents of a critically ill child, this research investigates the ability of the child's behavioral and emotional responses, sense of coherence, coping, religious belief, and social support in predicting psychological well-being in a Thai sample. Knowledge gained from this study is crucial for planning effective nursing intervention to enhance the psychological well-being of parents whose child is in a PICU that will in turn result in optimal parent participation in caring for and ensuring the well-being of their child hospitalized with a critical illness. Furthermore, the findings of this study will provide the significant information for planning further studies in this special population. 


\section{Materials and methods}

\section{Research design and sample}

This study used a correlational design to identify the factor(s) predicting psychological well-being among parents of a critically ill child in PICU. The factors examined the child's behavioral and emotional responses, sense of coherence, coping, religious belief, and social support of the parents.

The accessible population for this study consisted of mothers or fathers who were primary caregivers for a critically ill child aged 1 month - 15 years in the PICU of five tertiary hospitals located in Bangkok, Chiang Mai Province, and Ubon Ratchathani Province. Convenience sampling with inclusion criteria was used to select participants. The inclusion criteria included 1) having the age of 18 years or older; 2) being the primary caregivers for a critically ill child aged 1 month to 15 years; 3 ) having a child hospitalized in a PICU for more than $24 \mathrm{~h}$; 4) having normal mental functioning based on the Mental Status Questionnaire (MSQ) score of $\geq 8$ [39]; 5) being Buddhist; and 6) being able to read and write Thai.

The sample size for multiple regression was computed using the $G^{*}$ Power Program [40]. Since no previous study was available, the researcher used the moderate effect size (f2) of 0.15 , power for statistical analysis $(1-\beta) 0.80$, and a level of significance $(\alpha) 0.05$. Data analysis, estimated the satisfactory sample size to be 92 . The researcher added $10 \%$ additional participants to compensate for possible missing data [41], making the sample size 100.

\section{Conceptual framework}

The conceptual framework for this study was based on the SPM in caregivers developed by Pearlin and colleagues [23] and an extensive review of concepts including psychological well-being of caregivers, the child's behavioral and emotional responses, religious belief, sense of coherence, social support, and coping. The SPM had demonstrated its potential in explaining the relationship among factors related to the care situations and life-threatening situations of children and to examine the psychological well-being of parents who had a critically ill child. All factors were expected to have pooled effects leading to change of psychological well-being of parents (see Figure 1).

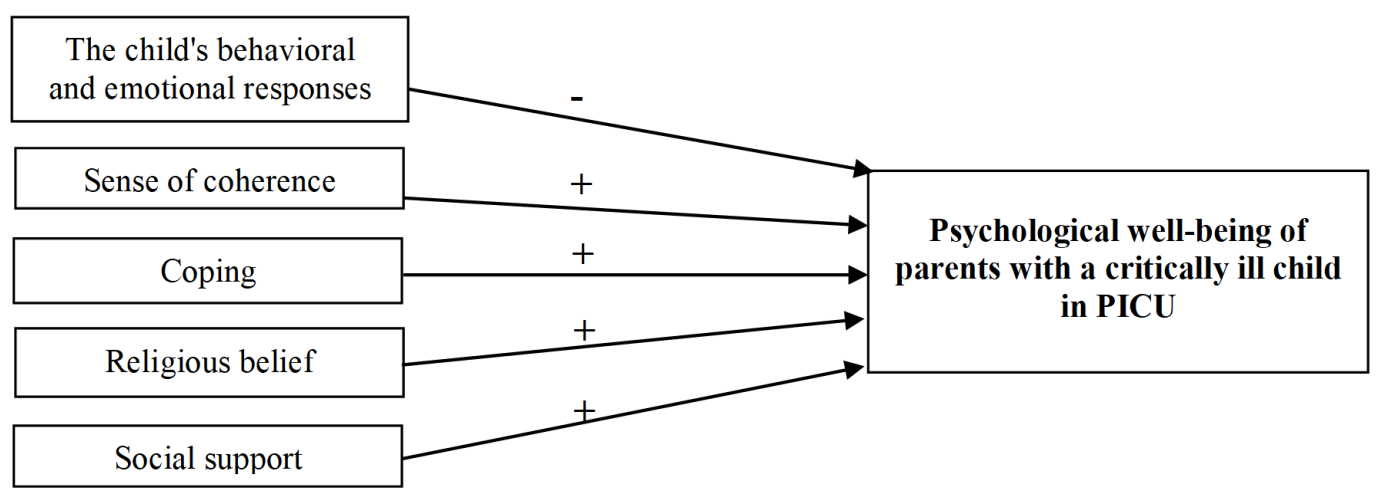

Figure 1 The conceptual framework of the psychological well-being of parents with a critically ill child in PICU. 


\section{Research instruments}

Seven research instruments were used to collect data as follows:

The Demographic Data Recording Form was developed by the researchers for gathering the child's demographic data, including age, gender, education, diagnosis, medications, and the number of PICU admissions, as well as the parents' demographic data, including relationship with a child, age, marital status, occupation, education background, family income, prior experience in caring for a hospitalized child, and number of children.

The Child's Behavioral and Emotional Responses Scale was a part of the Parental Stressor Scale: PICU (PSS: PICU) developed by Carter and Miles in 1989 [42]. The whole scale contained 37 items with seven subscales measuring parents' perception of seven stressors associated with having the child admitted in a PICU, including the child's appearance, sights and sounds, procedures, behaviors of profession staff, parental role, communication of professional staff, and the child's behavioral and emotional responses. The Child's Behavioral and Emotional Responses Scale included 10 Likert-type questions with 6-point responses ranging from 0 (not stressful) to 5 (extremely stressful). Only the Child's Behavioral and Emotional Responses Subscale, translated into a Thai version by the researchers, was used to assess the child's physical and emotional responses as perceived by parents while the child was hospitalized in a PICU. This instrument was translated into Thai and assured the translation accuracy by using back-translation method. The possible scores of the Child's Behavioral and Emotional Responses Scale ranged from 0 to 50. High scores represented high level of the child's behavioral and emotional responses. Regarding the psychometric properties of the original instrument, the factor analysis showed the seven-factor structure that confirmed its construct validity. The internal consistency showed the Cronbach's alpha coefficient of 0.95 for whole scale, and 0.97 for child's behaviors and emotions subscale [42]. In this study, the Cronbach alpha coefficient was 0.89 in the pilot sample and 0.80 for the study sample.

The Sense of Coherence Scale-Short Form (SOC-13), Thai Version, was translated from the original version of SOC-13 into Thai by Hanucharurnkul and colleagues [43]. The scale was used to measure the level of the parents' sense of coherence. It consisted of 13 items, including comprehensibility (5 items), manageability (4 items) and meaningfulness (4 items). Prior to calculating the total score, the scores of five negative items were reversed. This instrument was a seven-point rating scale, with possible responses to each item ranging from 1 (not at all) to 7 (a great deal). The possible scores ranged from 13 to 91 . A high score presented a high level of a sense of coherence. Regarding psychometric properties, this instrument was tested in many samples from which its reliability, validity, and feasibility of both versions were acceptable. The internal consistency of the SOC-29 tested in 26 studies showed that the Cronbach's alpha coefficient ranged from 0.82 to 0.95 , whereas that for the SOC-13 tested in 16 studies showed the Cronbach's alpha coefficient of 0.74 to 0.91 . The criterion-related validity was showed by the significant correlations of the SOC score with four parts: 1) a global orientation to oneself and one's environment ( $\mathrm{r}$ $=0.2-0.63), 2)$ perceived stressors $(r=0.22-0.56), 3)$ health, illness, and well-being $(0.12-0.71), 4)$ attitudes and behaviors $(\mathrm{r}=0.14-0.53)$ [44]. In this study, the Cronbach alpha coefficient was 0.81 in the pilot sample and 0.75 for the study sample.

The Jalowiec Coping Scale (JCS) was developed and revised by Jalowiec [45] and was translated into Thai by Mingkwan and colleagues using back-translation technique [46]. The JCS was used to measure coping strategies of parents. It consisted of 36 items and comprises three subscales including confrontive coping (13 items), emotive coping ( 9 items), and palliative coping (14 items). The JCS was a 5-point Likert scale ranging from 1 (never use) to 5 (almost always use). The possible scores ranged from 36 to 180, with higher scores indicating more frequent use of coping. The original scale had been tested for its construct validity and reliability. The confirmatory factor analysis (CFA) showed a three-factor structure, including confrontive coping, emotive coping, and palliative coping. The Cronbach's alpha coefficients ranged from $0.75-0.95[45,46]$. In this study, The Cronbach's alpha coefficients was 0.91 in the pilot sample and 0.86 for the study sample.

The Buddhist Belief Questionnaire was developed by the researchers based on literature review to measure the parents' religious belief. This questionnaire consisted of 18 items that were rated on a 5-point scale ranging from 1 (slightly agree) to 5 (strongly agree). The questionnaire had two components: the 
belief in four components of saddhā (14 items) and the belief in the three characteristics of existence (4 items). Seventeen items were positive, and one item was negative. The possible score ranged from 18 to 90. Higher scores indicated higher levels of religious beliefs. The content validity was evaluated by six experts who specialized in Buddhism including two nursing instructors, one Buddhist instructor, and three Buddhist monks. The content validity index (CVI) was calculated for both item and scale levels. As a result, the I-CVI ranged from 0.83 to 1.00 , and the S-CVI was 0.99 . In this study, the Cronbach alpha coefficient was 0.91 in the pilot sample and 0.95 for the study sample.

The Modified Version of Social Support Questionnaire, Thai Version was done by Hanucharurnkul [47] from the SSQ Part II developed by Schaefer, Coyne, and Lazarus and from the Norbeck Social Support Questionnaire [NSSQ] developed by Norbeck, Lindsy, and Carrieri [47]. The original questionnaire was used to assess perceived social support from three social networks: family members, friends and relatives, and health care providers. The questionnaire consisted of 21 items including informational support (3 items), emotional support (12 items) and tangible support (6 items). The participants were asked to rate the level of support received from each social network. The items had a 5point scale ranging from 0 (never received support) to 4 (almost always received support). A possible score ranged from 0 to 84 . High scores reflected a high level of perceived social support. The psychometric properties showed that the content validity index (CVI) was 0.86 and the Cronbach's alpha coefficient for the whole scale was 0.88 [48]. In this study, the Cronbach alpha coefficient was 0.89 in the pilot sample and 0.92 for the study sample.

The Psychological General Well-Being Index (PGWBI) developed by Dupuy [19] was used to assess the parents' subjective well-being. Health and quality of life of general populations and people with chronic disease can be assessed by PGWBI. The PGWBI was translated into many languages and cross-culturally validated for the use in many countries under the coordination of the Mapi Research Institute [49]. It consisted of 22 items and covered 6 dimensions of well-being, including anxiety (5 items), depression (3 items), positive well-being (4 items), self-control (3 items), vitality (4 items), and general health ( 3 items). Participants were asked about their feelings in general during the past month. It was a 6-point scale ranging from 0 - 5 scores that represented frequency of feelings. The possible score ranged from 0 to 110. The high scores represented high level of psychological well-being. For the psychometric properties of the original version of PGWBI, the concurrent validity showed the negative correlation coefficients between the PGWBI and fourteen mental health scales ranged from 0.52 to 0.80 . The reliability of the PGWBI by measures of the Cronbach's alpha coefficients ranged from 0.90 to 0.94 [19]. In this study, the Cronbach alpha coefficient was 0.93 in the pilot sample and 0.92 for the study sample.

\section{Procedures}

After getting approval from the Research Ethical Committee of the Faculty of Nursing, Chiang Mai University, as well as from the five hospitals, the data collection was done by the researchers and four trained research assistants. The researchers or the research assistants screened for the eligible participants who met the inclusion criteria. On the second day after PICU admission, potential participants were informed about the study and their ethical rights. Those consenting to participate signed a consent form. Then, either the researchers or the research assistants distributed the questionnaires to the participants and explained how to answer the questionnaires. The questionnaires were given in the following order: Demographic Data Recording Form, the Child's Behavioral and Emotional Responses Scale, the Sense of Coherence Scale-Short Form (SOC-13), Thai Version, the Jalowiec Coping Scale (JCS), the Buddhist Belief Questionnaire, the Modified Version of Social Support Questionnaire, Thai Version, and the Psychological General Well-Being Index (PGWBI). The total time required for completing the questionnaires was approximately 30 - $40 \mathrm{~min}$. At the same time, the researchers or the research assistants collected medical data from the patient's records and filled in the Demographic Data Recording Form. After the participants returned the questionnaires, the researchers or the research assistants rechecked for the completion of all the questionnaires and only the completed questionnaires were used for data analysis. The data were collected from December, 2016 to April, 2017. 


\section{Data Analysis}

Descriptive statistics were used to assess the demographic data of the participants and examine the levels of the study variables. The Kolmogorov-Smirnov test showed the normality of the child's behavioral and emotional responses, sense of coherence, social support, and psychological well-being, while that of coping and religious belief data was not demonstrated. Pearson's product moment correlation coefficient was used to analyze the bivariate relationship between the child's behavioral and emotional responses, sense of coherence, social support, and psychological well-being, while Spearman's rank correlation coefficient was used to determine the relationship between coping, religious belief, and psychological well-being. Moreover, hierarchical multiple regression analysis was used to examine how the predictability of the child's behavioral and emotional responses, sense of coherence, coping, religious belief, and social support affect the psychological well-being among parents of a critically ill child in PICU.

\section{Results and discussion}

\section{Results}

The sample of this study included 100 parents of a critically ill child recruited from five PICUs of five tertiary hospitals. The majority of the participants in this study were mothers (79\%), married (82\%), and with ages ranging from 18-56 years with a mean age of 33.01 (SD =7.85). Nearly half of the participants $(46 \%)$ graduated from secondary school and $23 \%$ of participants were primary school graduates. Twenty-seven participants $(27 \%)$ were laborers and $24 \%$ were housewives. The majority of the participants $(48 \%$ ) had a monthly family income of less than 10,000 baht. With regard to the characteristics of the family, $41 \%$ of participants had two children under their responsibility (including the critically ill child). Seventy-six participants $(76 \%)$ did not have prior experience in caring for a hospitalized child in a PICU and $86 \%$ of them perceived the severity of child's illness as severe.

Regarding the critically ill children's demographic, just over half of them were boy (56\%), and with ages ranging from 1 month to 14.10 years (mean $=4.10$ years, $\mathrm{SD}=4.80$ years). Thirty-eight children (38\%) were infants and $22 \%$ were toddlers. Most children (70 \%) were not attending school and $18 \%$ of them were in primary school. With regard to their clinical characteristics, the most common problems for PICU admission were respiratory problems requiring respiratory support (46\%), postoperative complications requiring close observation and monitoring (14\%), and sepsis and septic shock (12\%). Most children had mechanical ventilator support (77\%), central line catheter insertion $(52 \%)$, Foley's catheter insertion (51\%), receiving antibiotics $(91 \%)$, bronchodilators $(63 \%)$, and sedatives $(55$ $\%$ ). In addition, $76 \%$ of them were admitted to PICU for the first time.

The scores derived from measuring the child's behavioral and emotional responses, sense of coherence, coping, and psychological well-being and were at moderate levels with means of $29.58(\mathrm{SD}=$ $8.60), 56.64(\mathrm{SD}=11.61), 104.23(\mathrm{SD}=15.51)$, and 63.08 ( $\mathrm{SD}=15.41)$, respectively. In addition, the scores of religious belief and social support were high with means of $77.78(\mathrm{SD}=10.65)$ and $62.55(\mathrm{SD}=$ 11.90), respectively (see Table 1).

Table 1 Range, Mean, and Standard Deviation of Studied Variables

\begin{tabular}{|c|c|c|c|c|c|c|}
\hline Variables & Possible score & Actual score & Mean & SD & Median & IQR \\
\hline $\begin{array}{l}\text { The child's behavioral and } \\
\text { emotional responses }\end{array}$ & $0-50$ & $7-48$ & 29.58 & 8.60 & & \\
\hline Sense of coherence & $13-91$ & $30-85$ & 56.64 & 11.61 & & \\
\hline Coping $^{\mathrm{a}}$ & $36-180$ & $69-136$ & 104.23 & 15.51 & 107.00 & 18.75 \\
\hline Religious belief ${ }^{\text {a }}$ & $18-90$ & $53-90$ & 77.78 & 10.65 & 79.50 & 14.75 \\
\hline Social support & $0-84$ & $36-84$ & 62.55 & 11.90 & & \\
\hline Psychological well-being & $0-110$ & $29-100$ & 63.08 & 15.41 & & \\
\hline
\end{tabular}

Note. ${ }^{\mathrm{a}}=$ not normally distributed 
With regard to the correlation among the study variables, the findings demonstrated that the child's behavioral and emotional responses had a low and negative relationship with psychological well-being ( $\mathrm{r}$ $=-0.20, \mathrm{p}<0.05)$. Sense of coherence, social support, and religious belief had a moderately positive relationship with psychological well-being $\left(r=0.42,0.36, r_{s}=0.27, p<0.01\right.$ respectively), while coping had a low and positive relationship with psychological well-being $\left(r_{s}=0.20, p<0.05\right)$. In addition, the findings showed that no relationship was found between age, education, income and psychological wellbeing of parents $\left(r_{s}=0.10,-0.08,-0.08, p>0.05\right.$, respectively) (see Table 2 ).

Table 2 Relationships between Selected Factors and Psychological Well-being of Parents.

\begin{tabular}{lcc}
\hline \multicolumn{1}{c}{ Variables } & r & p-value \\
\hline Age & $0.10^{\mathrm{a}}$ & 0.16 \\
Education & $-0.08^{\mathrm{a}}$ & 0.21 \\
Income & $-0.08^{\mathrm{a}}$ & 0.21 \\
The child's behavioral and emotional responses & -0.20 & 0.03 \\
Sense of coherence & 0.42 & 0.00 \\
Coping & $0.20^{\mathrm{a}}$ & 0.02 \\
Religious belief & $0.27^{\mathrm{a}}$ & 0.01 \\
Social support & 0.36 & 0.00 \\
\hline
\end{tabular}

Note. $\mathrm{a}=$ Spearman's rank correlation analysis $\left(\mathrm{r}_{\mathrm{s}}\right)$

In this study, the findings showed that no relationship was found between the parents' demographic data and psychological well-being of parents (see Table 2). Therefore, the researcher did not select the parents' demographic data for analysis in multiple regression. From the hierarchical multiple regression, the multiple coefficient of determination $\left(\mathrm{R}^{2}\right)$ indicated that religious belief predicted $10 \%$ of the variation of psychological wellbeing of parents with a critically ill child in pediatric intensive care unit. When the child's behavioral and emotional responses was added, $17 \%$ of the variance was accounted for and when sense of coherence, coping, and social support were added to the equation, $36 \%$ of the variance was accounted for. F-test for all three models was statically significant. Therefore, assessment all five variables were able to predict psychological wellbeing of parents with a critically ill child in pediatric intensive care unit. When compared among these five variables, the factors that made significant contributions to the model (in this order) were religious belief $(\beta=0.29, p<0.01)$, sense of coherence $(\beta$ $=0.27, \mathrm{p}<0.01)$, the child's behavioral and emotional responses $(\beta=-0.24, \mathrm{p}<0.01)$, social support $(\beta=$ $0.22, \mathrm{p}<0.05)$, and coping $(\beta=0.17, \mathrm{p}<0.05)$ (see Table 3). 
http://wjst.wu.ac.th

Table 3 The Hierarchical Multiple Regression Analysis for Psychological Well-being of Parents.

\begin{tabular}{|c|c|c|c|c|c|c|c|}
\hline Predictive variables & $\mathbf{R}^{2}$ & $\begin{array}{c}\mathbf{R}^{2} \\
\text { change }\end{array}$ & SEE & F-test & $\begin{array}{c}\text { Regression } \\
\text { coefficient }\end{array}$ & $\boldsymbol{\beta}$ & T-test \\
\hline $\begin{array}{l}\text { Predictor: psychological } \\
\text { well-being } \\
\text { Model 1: } \\
\text { - Religious belief }\end{array}$ & 0.10 & 0.10 & 14.66 & $11.35^{* *}$ & 5.19 & $0.32 * *$ & $3.37 * *$ \\
\hline $\begin{array}{l}\text { Model 2: } \\
\text { - Religious belief } \\
\text { - child's behavioral and } \\
\text { emotional responses }\end{array}$ & 0.17 & 0.07 & 14.19 & $9.91 * *$ & $\begin{array}{c}5.94 \\
-0.47\end{array}$ & $\begin{array}{c}0.37 * * \\
-0.26 * *\end{array}$ & $\begin{array}{l}3.91 * * \\
-2.78 * *\end{array}$ \\
\hline $\begin{array}{l}\text { Model 3: } \\
\text { - Religious belief } \\
\text { - child's behavioral and } \\
\text { emotional responses } \\
\text { - sense of coherence } \\
\text { - coping } \\
\text { - } \text { social support }\end{array}$ & 0.36 & 0.19 & 12.62 & $10.73 * *$ & $\begin{array}{r}4.59 \\
-0.43 \\
0.36 \\
2.69 \\
0.29\end{array}$ & $\begin{array}{c}0.29 * * \\
-0.24 * * \\
0.27 * * \\
0.17 * \\
0.22 *\end{array}$ & $\begin{array}{c}3.35 * * \\
-2.79 * * \\
3.07 * * \\
2.53 * \\
2.05 * *\end{array}$ \\
\hline
\end{tabular}

Note. ${ }^{*} \mathrm{p}<0.05 ; * * \mathrm{p}<0.01, \mathrm{SEE}=$ Standard error of estimate

\section{Discussion}

The results of this study suggest that religious belief, the child's behavioral and emotional responses, sense of coherence, coping, and social support were the best predictors for psychological wellbeing and altogether could explain $36 \%$ of the variance in psychological well-being among parents of a critically ill child. This finding supported the conceptual framework, which explained that the child's behavioral and emotional responses were one of the greatest stressors for parents in the PICU. A critical illness is a sudden, unexpected, and often life-threatening occurrence for both children and their families, which threatens their psychological state. During PICU hospitalization, the child's behavioral and emotional responses comprise the child responds physically and emotionally to pain that is associated with many invasive procedures, discomfort or other serious conditions by crying, being frightened and restless, demanding behavior, acting or looking in a painful manner, being uncooperative, being unable to talk or cry, angry and sad [15]. A child's critical illness and behaviors can trigger a stress response in their families [50]. When the child's condition has worsened, their parents are more stressed or threatened in terms of their psychological state. From literature review, the child's behavioral and emotional responses were found to be related to parental stress that affected their psychological well-being [51]. Religious beliefs of Buddhists helped the parents understand and accept the child's illness situation as unavoidably caused by "karma" of both the child and the parents themselves [52]. Feeling of guilt from not taking very good care of the child leading to the child's illness may also be found in these parents and could be alleviated by religious belief. The higher the religious belief, indicated a higher level of psychological well-being. For Buddhist caregivers, religious belief could minimize stress [53].

Regarding a sense of coherence (SOC) that was considered as an intrapersonal resource for a person's handling the current situation [54], the moderate level was reported in the parents. Theoretically, the parents with high SOC are able to understand the child's illness situations and explain what has occurred. In addition, SOC enables the parents to feel that the stimuli or stress is meaningful, explainable, and solvable. The parents with high SOC are more likely to the ability to make sense of the stressful situation or the life-threatening condition of their children, deal with this situation by using generalized 
resistance resources or available resources, and select the appropriate coping strategies to cope effectively with a stressor [25]. Therefore, the stressful could be managed well. Consistent with previous studies, SOC was found to be related to the psychological well-being of stroke caregivers [26] and was negatively related to stress and depression of mothers with autistic children [27], and mothers of children with intellectual disability [28]. For social support, the high level was identified in the parents. Social support, in the SPM, plays an important role in protecting persons from their stressful events and maintaining their well-being [55]. Available social supports helped the parents deal with stressful situations. Moreover, many previous studies showed that some types of social support, particularly information support, had an effect on psychological state of parents who had a severely ill child in PICU [56,57]. Coping is one of the mediators of stress leading to a positive outcome of the caregiving situation [23]. When the parents were confronted with a stressful situation in the PICU, they were sometimes able to avoid negative psychological state by using effective coping strategies. They used cognitive process to appraise the situation. Stress appraisal can be harm/loss, threatening or challenging [29]. In this study, even though the care situation was stressful, the positive outcome of coping that was psychological well-being was still high. The high psychological well-being may be due to the effect of SOC, religious belief, and social support. In this study, the moderate relationship was reported between those factors and parents' psychological well-being. Moreover, the parents in this study had moderate level of coping meaning that they were more likely to use appropriate coping strategies.

This study demonstrated that only $36 \%$ of the variance in the psychological well-being of parents was explained by the five variables. Therefore, there were still other potential variables in this phenomenon that influenced psychological well-being among parents of a critically ill child in the PICU. One study of Vrolarn [22] showed that parents' education, perception of uncertainty in illness, and emotional-focused coping were important predictors and accounted for $38.81 \%$ of the variance in psychological well-being of parents with children admitted in the intensive care unit. Also, a study by Cheon [58] in American mothers with preterm infants revealed that maternal stress could explain $43 \%$ of the variance in anxiety, $22 \%$ in depression, and $24 \%$ in general well-being. Therefore, the parents' education, perception of uncertainty in illness, emotional-focused coping, and maternal stress might be other significant factors that could predict the psychological well-being of parents whose child was hospitalized in a PICU and need to be examined further. The limitation of this cross-sectional study is that the sample was purposively selected only from tertiary hospitals; thus, this may limit the generalizability of the findings with regard to hospitals with other care levels.

\section{Implication of this knowledge}

The findings can be useful for knowledge base of pediatric nursing regarding factors influencing psychological well-being among parents of a critically ill child in Pediatric Intensive Care Unit in Thailand and can help guide development of an intervention program for this population. Based on this findings, PICU nurses should develop a program for parents of a critically ill child in PICU that focuses on reducing perceived child's behavioral and emotional negative response, and enhancing religious belief, sense of coherence, effective coping, and social support. Moreover, PICU nurses should regularly assess the parents' psychological well-being, so that the prompt support can be provided.

For nursing research, the findings of the present study are the information that nursing researchers can use to plan further research studies to identify a causal model of psychological well-being. Also, the researcher can investigate more on other predictors for psychological well-being in parents. Additionally, future studies need to consider the use of an experimental design to test the effects of a program focusing on the modification of five predictors for enhancing parents' psychological well-being. 
http://wjst.wu.ac.th

\section{Conclusions}

The result revealed that religious belief, the child's behavioral and emotional responses, sense of coherence, coping, and social support predicted $36 \%$ of the variance in the psychological well-being of parents of a critically ill child. It is vital to note that other variables may affect psychological well-being of parents. Therefore, further empirical studies are needed to explore, examine, and identify those variables for their predictability and causality to psychological well-being. However, the research outcome as the SPM can be used as a guideline for further studies and practices to handle with parents' stress when they are in critical situation or enhance psychological well-being of parents whose child is hospitalized in PICU.

\section{Acknowledgements}

The authors would like to thank all participants for their cooperation in this study. Our deepest gratitude goes to my research assistants and health care providers at Ramathibodi Hospital, Queen Sirikit National Institute of Child Health, Bhumibol Adulyadej Hospital, Maharaj Nakorn Chiang Mai Hospital, and Suppasitiprasong Hospital for their cooperation in the data collection.

\section{References}

[1] D Stawon. Intensive care unit administration. In: D Stawon, C Loahapun, P Sengarun and S Kunathai (Eds.). Pediatric Critical Care. Beyond Enterprise, Bangkok, 2002, p. 12-21.

[2] Ramathibodi Hospital Statistic. Statistic of admission rate in the PICU. Bangkok, Faculty of Medicine Ramathibodi Hospital, Thailand, 2017.

[3] Maharaj Nakorn Chiang Mai Hospital Statistic. Statistic of admission rate in the PICU. Chiang Mai, Maharaj Nakorn Chiang Mai Hospital, Thailand, 2017.

[4] G Colville, J Darkins, J Hesketh, V Bennett, J Alcock and J Noyes. The impact on parents of a child's admission to intensive care: Integration of qualitative findings from a cross-sectional study. Intensive Crit. Care Nurs. 2009; 25, 72-9.

[5] U Jintrawet. 2005, Parental Practices during Their Child's Admission to Pediatric Intensive Care Unit. Ph. D. Dissertation. Chiang Mai University, Chiang Mai, Thailand.

[6] M Shudy, ML de Almeida, S Ly, C Landon, S Groft, TL Jenkins and CE Nicholson. Impact of pediatric critical illness and injury on families: A systematic literature review. Pediatrics 2006; 118, S203-S218.

[7] R Board and N Ryan-Wenger. Long-term effects of pediatric intensive care unit hospitalization on families with young children. Heart Lung 2002; 31, 53-66.

[8] M Huhtala, R Korja, L Rautava, L Lehtonen, L Haataja, H Lapinleimu and P Rautava. Healthrelated quality of life in very low birth weight children at nearly eight years of age. Acta Paediatr. 2015; 105, 53-9.

[9] BM Melnyk, L Alpert-Gillis, NF Feinstein, HF Crean, J Johnson, E Fairbanks, L Small, J Rubenstein, M Slota and B Corbo-Richert. Creating opportunities for parent empowerment: Program effects on the mental health/coping outcomes of critically ill young children and their mothers. Pediatrics 2004; 113, 597-607.

[10] M Mirghafourvand, E Ouladsahebmadarek, MB Hosseini, S Heidarabadi, M Asghari-Jafarabadi, and S Hasanpour. The effect of creating opportunities for parent empowerment program on parent's mental health: A systematic review. Iran J. Pediatr. 2017; 27, e5704.

[11] J Gonya, E Martin, R McClead, L Nelin and E Shepherd. Empowerment programme for parents of extremely premature infants significantly reduced length of stay and readmission rates. Acta Paediatrica 2014; 103, 727-31.

[12] SY Lee, KA Lee, SH Rankin, SJ Weiss and A Alkon. Sleep disturbance, fatigue, and stress among Chinese-American parents with ICU hospitalized infants. Issues Ment. Health Nurs. 2007; 28, 593605. 
http://wjst.wu.ac.th

[13] M Busse, K Stromgren, L Thorngate and KA Thomas. Parents' responses to stress in the neonatal intensive care unit. Crit. Care Nurs. 2013; 33, 52-9.

[14] SY Lee and LP Kimble. Impaired sleep and well-being in mothers with low birth Weight Infants. J. Obstet. Gynecol. Neonatal. Nurs. 2009; 38, 676-85.

[15] MS Miles and MC Carter. Sources of parental stress in pediatric intensive care units. Fall 1982; 11, 65-9.

[16] CD Ryff. Happiness is everything, or is it? Explorations on the meaning of psychological wellbeing. J. Pers. Soc. Psychol. 1989; 57, 1069-81.

[17] CD Ryff. Psychological well-Being revisited: Advances in science and practice. Psychother Psychosom. 2014; 83, 10-28.

[18] CLM Keyes. Psychological Well-being. In: JE Birren (Ed). Encyclopedia of Gerontology. $2^{\text {nd }} \mathrm{ed.}$ Elsevier, Amsterdam, 2007, p. 399-406.

[19] HJ Dupuy. The Psychological General Well-being (PGWB) Index. In: NK Wenger, MECD Furburg and J Elinson (Eds.). Assessment of Quality of Life in Clinical Trials of Cardiovascular Therapies. Le Jacq, New York, 1984, p. 170-83.

[20] CLM Keyes. Mental Health as a Complete State: How the Salutogenic Perspective Completes the Picture. In: GF Bauer and O Hämmig (Eds). Bridging Occupational, Organizational and Public Health. Springer, Dordrecht, 2014, p. 179-92.

[21] World Health Organization, Available at: http://www.who.int/features/factfiles/mental_health/en/, accessed July 2018.

[22] V Vrolarn. 1992, Perception of Uncertainty in Illness, Coping and General Well-being of Parents with Children Admitted in Intensive Care Unit. Master's Thesis. Mahidol University, Bangkok, Thailand.

[23] LI Pearlin, JT Mullan, SJ Semple and MM Skaff. Caregiving and the stress process: An overview of concepts and their measures. Gerontologist 1990; 30, 583-94.

[24] M Menne. 2006, A Stress Process Model of Chronic Illness: Understanding the Well-being and Decision-making Involvement of Individuals with Dementia. Ph. D. Dissertation. Case Western Reserve University, USA.

[25] A Antonovsky. Unraveling the Mystery of Health: How People Manage Stress and Study Well. Jossey-Bass Publishers, San Francisco, 1987.

[26] G Forsberg-Warleby, A Moller and C Blomstrand. Spouses of first-ever stroke victims: Sense of coherence in the first phase after stroke. J. Rehabil. Med. 2002; 34, 128-33.

[27] WWS Mak, AHY Ho and RW Law. Sense of coherence, parenting attitudes and stress among mothers of children with autism in Hong Kong. J. Appl. Res. Intellect. Disabil. 2007; 20, 157-67.

[28] MB Olsson and CP Hwang. Sense of coherence in parents of children with different developmental disabilities. J. Intellect. Disabil. Res. 2002; 46, 548-59.

[29] RS Lazarus and S Folkman. Stress, Appraisal, and Coping, Springer, New York, 1984.

[30] JM Latour, JB van Goudoever, BE Schuurman, MJ Albers, NA van Dam, E Dullaart, M van Heerde, CW Verlaat, EM van Vught and JA Hazelzet. A qualitative study exploring the experiences of parents of children admitted to seven Dutch pediatric intensive care units. Intensive Care Med. $2011 ; \mathbf{3 7}, 319-25$.

[31] S Joshi and S Kumari. Religious beliefs and mental health: An empirical review. Delhi Psychiat. J. $2011 ; 14,40-50$.

[32] E Colón-Bacó. The strength of religious beliefs in important for subjective well-being. Undergraduate Econ. Rev. 2010; 6, 11.

[33] National Statistical Office. Available at: http://www.nso.go.th, accessed January 2018.

[34] HG Koenig. Religion, spirituality and psychotic disorders. Arch. Clin. Psychiat. 2007; 34, 40-8.

[35] A Kaliampos and P Roussi. Religious beliefs, coping, and psychological well-being among Greek cancer patients. J. Health Psychol. 2017; 22, 754-64.

[36] C Schaefer, JC Coyne and RS Lazarus. The health-related functions of social support. Int. J. Behav. Med. 1981; 4, 381-406. 
http://wjst.wu.ac.th

[37] NL Chappell and RC Reid. Burden and well-being among caregivers: Examining the distinction. Gerontologist 2002; 42, 772-80.

[38] S Boonyawat and R Sunsern. Factors influencing well-being of Thalassemic children's caregivers at home in the Eastern region (in Thai). J. Facul. Nurs. Burapha Univ. 2005; 1, 55-70.

[39] RL Khan, AI Goldfarb, M Pollack and A Peck. Brief objective measures for the determination of mental status in the aged. Am. J. Psychiat. 1960; 117, 326-8.

[40] F Faul, E Erdfelder, A Buchner and AG Lang. Statistical power analyses using G*Power 3.1: Tests for correlation and regression analyses. Behav. Res. Meth. 2009; 41, 1149-60.

[41] JF Hair, WC Black, BJ Babin and RE Anderson. Multivariate data analysis: A global perspective. $7^{\text {th }}$ ed. New Jersey, Pearson Education, 2010.

[42] MC Carter and MS Miles. The parental stressor scale: Pediatric intensive care unit. Fall 1989; 18, 187-98.

[43] S Hanucharurnkul, P Intarasombut and P Putwatana. Daily hassles, sense of coherence and general well-being among nursing faculty members of university (in Thai). Thai J. Nurs. 1989; 38, 169-90.

[44] A Antonovsky. The structure and properties of the sense of coherence scale. Soc. Sci. Med. 1993; 36, 725-33.

[45] A Jalowiec. Confirmatory Factor Analysis of the Jalowiec Coping Scale. In: CF Waltz and OL Strickland (Eds.). Measurement of Nursing Outcomes: Measurement Client Outcomes. Vol I. Spinger, New York, 1988, p. 287-308.

[46] P Mingkwan. 1999, Stress and Coping in the Elderly Stroke Patients. Master's Thesis. Chiang Mai University, Chiang Mai, Thailand.

[47] S Hanucharurnkul. 1988, Social Support, Self-care, and Quality of Life in Cancer Patients Receiving Radiotherapy in Thailand. Ph. D. Dissertation. The Wayne State University, USA.

[48] C Santawaja. 2002, A Casual Model of Psychosocial Adjustment in Post Radiotherapy Cervical Cancer Women. Ph. D. Dissertation. Mahidol University, Bangkok, Thailand.

[49] Mapi Research Institute. Available at: https://mapigroup.com, accessed January 2016.

[50] MF Hazinski. Nursing Care of the Critically ill Child. $3^{\text {rd }}$ ed. Mosby, Missouri, 2013.

[51] M Aamir, K Mittal, JS Kaushik, H Kashyap and G Kaur. Predictors of stress among parents in pediatric intensive care unit: A prospective observational study. Indian J. Pediatr. 2014; 81, 116770.

[52] PA Payutto. Dictionary of Buddhism (in Thai). $11^{\text {th }}$ ed. Sahadhmmika, Bangkok, 2002.

[53] RS Gray, L Hahn, S Thapsuwan and N Thongcharoenchupong. Strength and stress: Positive and negative impacts on caregivers for older adults in Thailand. Australas J. Age. 2016, 35, E7-E12.

[54] B Wheaton. The Stress Process as a Successful Paradigm. In: Avison WR, CS Aneshensel, S Schieman and B Wheaton (Eds). Advances in the Conceptualization of the Stress Process: Essays in Honor of Leonard I. Pearlin. Spinger, New York, 2010, p. 231-52.

[55] LI Pearlin. The Stress Process Revisited: Reflections on Concepts and Their Interrelationships. In: CS Aneshensel and JC Phelan (Eds.). Handbook of the Sociology of Mental Health, Springer, New York, 1999, p. 395-415.

[56] A Aksornsri, W Thampaanichawat, K Wichiencharoen and P Sangperm. The effects of concreteobjective information on parental anxiety and parental participation in care for children in pediatric intensive care unit (in Thai). J. Nurs. Sci. 2012; 30, 80-9.

[57] N Beheshtipour, SM Baharlu, S Montaseri and SMR Ardakani. The effect of the educational program on Iranian premature infants' parental stress in a neonatal intensive care unit: A doubleblind randomized controlled trial. Int. J. Commun. Based Nurs. Midwifery 2014; 2, 240-50.

[58] K Cheon. 2012, Psychological Well-being of Mothers with Preterm Infants. Ph. D. Dissertation. University of California, USA. 